In Luraghi, Silvia, Tatiana Nikitina and Chiara Zanchi (eds.). 2017. Space in Diachrony, 329-346. Amsterdam: John Benjamins.

\title{
Source-Location ambiguity and incipient decline in the recent evolution of the English directional particle away
}

\author{
Diana M. Lewis, Aix Marseille University
}

\begin{abstract}
This chapter reports on a corpus-based investigation of the evolution of spatial away over the Modern English period in the light of recent work on the expression of motion events. Three observations are made: firstly, a directional-locative polysemy develops, secondly productivity seems to stagnate, and thirdly, for a range of verbs, directional V-away seems to be being gradually replaced by V-off. The likely mechanisms behind these changes are discussed, and it is suggested that away may be an atypical directional particle in decline, possibly in the context of a reorganization or regularization of English directional particles.
\end{abstract}

Keywords: English; directional particle; motion event.

\section{Introduction}

English has a well-known set of spatial particles, such as up, down, along, across, away, in, out, through, off, on, under, over, round, etc., that has remained relatively stable over the centuries. The most salient and well-documented development has been the rise in idiomatic ${ }^{1}$ and aspectual uses, leading to multiple polysemies (Brinton 1988). Much less attention has been paid to the recent history of the older, spatial uses of the particles, which are often assumed to have remained more or less constant. The present study addresses the spatial uses of away and poses two main questions: first, whether, despite the apparent long-term stability of the particle, any patterns of change can be discerned, and second, if so, what mechanisms seem to have been instrumental, such as analogy (paradigmatic pressure for regularization) or 'linear fusion' (syntagmatic pressure which might lead to lexicalizations or idiomatization).

Semantically, a continuum of usage is found for many of the particles, from the 'real' location and movement in space of physical objects to purely aspectual uses. Diachronically the particles have evolved along typical grammaticalization lines from the physical towards the abstract, grammatical domain ( $v$. Brinton 1988). In Present-day English the continuum can be viewed for convenience as consisting of five areas: physical location or motion, fictive location or motion (Talmy 2000: 99ff.), abstract location or motion, idiomatic uses and aspectual uses. The spatial uses investigated here include the first three areas, which are semantically transparent (compositional) or semi-transparent and in some sense spatial. Fictive motion refers to situations in which the figure itself does not physically move, but the perceiver's focus of attention, for instance, moves as it takes in the situation, as in A ditch runs along the side of the path. Abstract spatial uses include cases originating in a type of hyperbolic imagery, such as The company would be wiser to find these new customers before chasing away the old ones, where some behaviour on the part of the company causes 
customers to keep away from its stores, and cases of abstract entities conceived as occupying locations, such as Mrs Gorman's arrival had chased away my fears, where the fears, although intangible, are conceived as exiting the person. The above characterization of the semantic continuum exhibited by most particles is crude and oversimplified but will suffice to indicate the scope of the study.

The next section outlines usage of away in Present-day English. Section 3 describes the corpus from which the data are drawn. Sections 4 and 5 deal with recent change in the frequencies and distribution of away. They present the findings from a corpus-based analysis of the particle over the Modern English period. Section 4 looks at the evolution of the semantics of away, and in particular at the development of its use in Locative contexts, while Section 5 focuses on the possible replacement of away by off. Section 6 considers motivations for the decline of away. Finally, section 7 summarizes the findings and suggests some ideas for further research.

\section{Away in Present-day English}

Away is normally described as a Source-oriented adverbial particle, along with out and off. It is said to be 'source-oriented' because a Source ground must be understood for the use of the particle to be felicitous. The Source may be either the default deictic centre of the discourse or recoverable from the context of use of away; or else it will be explicitly identified. Away contains within itself the notion of 'origo', the location from which the motion of the figure or trajector distances it.

Away may be regarded as an atypical English spatial particle insofar as it has a few characteristics that are not shared by the majority of English spatial particles. First, it is itself a lexicalization already present in Old English in the path expression onweg or awe ${ }^{2}$. Away to a Present-day English speaker may appear by its phonological form to belong with along, around, apart, aside, ahead, across, and so on, although the $-a$ is a historical remnant. Second, unlike the majority of the English spatial particles, it does not function as a preposition; in this respect there is an asymmetry between away (adverbial particle) and the closest it has to an opposite, towards (preposition), unlike other particle pairs such as up and down or on and off or above and below. Third, it differs from other source-oriented particles in that there is neither boundary-crossing as with out, nor sharp detachment as with off, a point that may be related to its lack of a true opposite in either back or towards.

In Present-day English, away is extremely multifunctional. It occurs as a directional particle for both self-motion (1) and caused motion (2), as a locative particle (3), an aspectual particle, both durative (bounded (4a) or unbounded (4b)) and inceptive (4c), and in very many idiomatic expressions such as those in (5). ${ }^{3}$

\section{Davey moved quite a long way away for his work}

(2) they'd moved the girl away to another ward

(3) They stayed away for a fortnight

(4) a. The sound faded away.

b. The nightingale was singing away.

c. If you have any questions, fire away. 

a. the men whiled away the time brewing tea on the pavement
b. put them straight away into the storage binders, please
c. A year later, ... the Benefits Agency will be up and away

The rest of the paper will focus on the spatial uses as outlined in the introduction. In the terms of Talmy's well-known typology of the expression of motion events, English is said to be a 'satellite-framed' language. Talmy $(1985,2000)$ identifies four main elements of the motion event situation: Motion, Figure, Path and Ground, reflecting the scenario where a Figure moves along a Path with respect to some Ground (featuring one or more landmarks). For the event described in (6), for instance, we will say that a Figure (the cat) moves (strode) along a Path (away from .. across .. into) with respect to three landmarks (the dog, the garden and the kitchen, respectively Source, Median and Goal of the motion).

The cat strode away from the dog, across the garden and into the kitchen.

The caused-motion construction exemplified in (7) likewise involves the motion of a Figure (the plates) with respect to a Ground (the table).

a. They took the plates away from the table

b. They took away the plates from the table

Different languages, according to Talmy's typology, preferentially lexicalize these elements in different ways. Some (Romance languages, for instance) tend to conflate Motion and Path into a verb (cf. Spanish, El gato se alejó del perro, and French, Le chat s'éloigna du chien, where the verbs alejarse and s'éloigner contain the notion 'motion away from'), and are therefore termed 'verb-framed languages'. Others, like English, tend to code the Path by a directional particle, or 'satellite', such as away, while the verb of motion often conflates Motion and a co-event 'manner of motion', as in stride. These Talmy terms 'satellite-framed languages'. 'Satellite' in Talmy's framework is defined by both semantic and syntactic features; the notion is intended to capture "a common function across one typological category of languages as the characteristic site .. for the expression of Path" (Talmy 2000: 102). That is, 'satellite' is a language-independent category encoding Path information and accompanying a verb of motion. ${ }^{4}$

Such a characterization of English lexicalization patterns in the expression of motion events suggests a view of a relatively homogeneous set of directional particles that combine quite freely with verbs of motion. But it is not clear that the particles do display such homogeneity or that they constitute a regular paradigm.

A great deal of the work on English Verb-particle (V-prt) combinations (or traditional 'phrasal verbs $^{15}$ ) has centred on how best to analyse them syntactically. The case of away in selfmotion (6) is variously analysed as [V away] [Prepositional Phrase (PP)], where V-prt is a lexicalized complex verb, as [V] [away from] [Noun Phrase (NP)], where away from is a complex preposition, or as [V] [away] [PP], a flat Verb Phrase (VP) (Jackendoff 2002:92 argues for the last structure for the V-prt construction, as the 'null hypothesis'). Where the ground is implicit (The cat strode away), the structure can likewise be analysed as [V away], or as [V] [away], where away is a full Adverbial Phrase (AdvP). Much discussion of V-prt syntax is tacitly based on an attempt to achieve maximum economy in the grammar. For a grammar in which the economy constraint is relaxed, a unified analysis is not required; rather, the structure can be considered to vary according to verb and to context. 
The alternation in (7) may reflect the fact that both away from and take away are strongly collocating pairs and the choice of (7a) or (7b) is at least partly an information-structural choice though dialectal variation may play a role too. (The pattern in (7a) is more frequent when the ground is mentioned.) Gries and Stefanowitsch (2004) find that the degree of idiomaticity of the V-prt item is one important factor in determining particle placement. We will assume therefore that (a) individual combinations and individual occurrences can have different structures and (b) that structures may change over time. ${ }^{6}$

Our concern in the following section will be the evolution of the use of away since the seventeenth century.

\section{The corpus and the data on away}

Data are taken from a diachronic corpus of informal registers of English from the mid sixteenth century to the 1980s. The corpus is outlined in Table 1 and the sources are listed in the appendix at the end of the chapter. The genres chosen for the diachronic study are drama, letters, diaries and journals, in an attempt to make the corpus as homogeneous as possible with regard to text types, and as close to the living language of the time as possible. A part of the twentieth century data (1960s onwards) is based on conversation, which of course is not directly comparable with those four genres, adequate samples of which were not available for the Present-day English period. The corpus has the disadvantage of being too small for conclusions to be drawn regarding any but the most frequent combinations of the particle.

\begin{tabular}{|l|l|l|}
\hline Period & Wordcount & $\mathbf{n =}$ \\
\hline $1600-39$ & 328193 & 162 \\
\hline $1640-79$ & 522494 & 286 \\
\hline $1680-1719$ & 446219 & 282 \\
\hline $1720-59$ & 364323 & 211 \\
\hline $1760-99$ & 321792 & 194 \\
\hline $1800-39$ & 379159 & 216 \\
\hline $1840-79$ & 447843 & 312 \\
\hline $1880-1919$ & 612636 & 434 \\
\hline $1920-1960 s$ & 671652 & 422 \\
\hline $1980 s$ & 437706 & 252 \\
\hline
\end{tabular}

Table 1. Corpus wordcounts and occurrences of 'away', by period.

The occurrences were coded first into five categories: self-motion, caused motion, verbless directional, location and aspectual/metaphorical. The boundary between the spatial and the aspectual/metaphorical was drawn on the basis of whether or not the speaker conceived of an identifiable figure moving in relation to at least one physical presence. Only the first four categories were retained for further coding, which included, when present, the verb, the event type, inversion (e.g. Away I home [1663]), and the Source and/or Goal expression. 
For the periodization of English, this paper follows for convenience what has become (albeit with some quibbling over the optimal dates) traditional practice, with the conventional abbreviations. From the middle of the twelfth century till 1500 is the Middle English (ME) period. Modern English (NE) corresponds to the period 1500-1945 (following Beal 2004) and is divided into Early Modern English (EModE), 1500-1700, and Late Modern English (LModE), 1700-1945. Present-day English (PDE) covers the period 1945 to the present day. For discussion of periodization see Penzl (1994) and Curzan (2012).

\section{Recent evolution of away}

\subsection{Origins and trends}

Away originates in a path expression meaning 'on one's way' or 'onward', but it had already lexicalized by the Old English period, when it is used to express moving from a place to some distance, or becoming detached from a place. In Middle English it comes to have pejorative connotations in its use in parting and loss contexts, and through the notion of moving into the distance it is associated with both durativity and dwindling to nothing, hence the aspectual uses. By Early Modern English away is used in a wide range of both spatial and non-spatial contexts. Its older function as a directional, coding movement from a source or deictic centre, remains. In the Modern English period data examined here, no radical change is evidenced in the token frequencies or construction types of spatial away, but there is evidence of shifting distributions (section 4.2) and of an incipient decline in productivity.

In Early Modern English, away was among the most frequent of particles, along with back, down, forth, in, off, on, out, over and up (Claridge 2000; Hiltunen 1994). Token frequency has remained relatively stable. But following a rise during the nineteenth century, a decline seems to have set in from the beginning of the twentieth century, for both spatial and non-spatial uses (Figure 1) ( $c f$. Rodriguez Puente 2013:174, 399, who, based on the whole Archer corpus, finds a decline in frequency since the late nineteenth century).

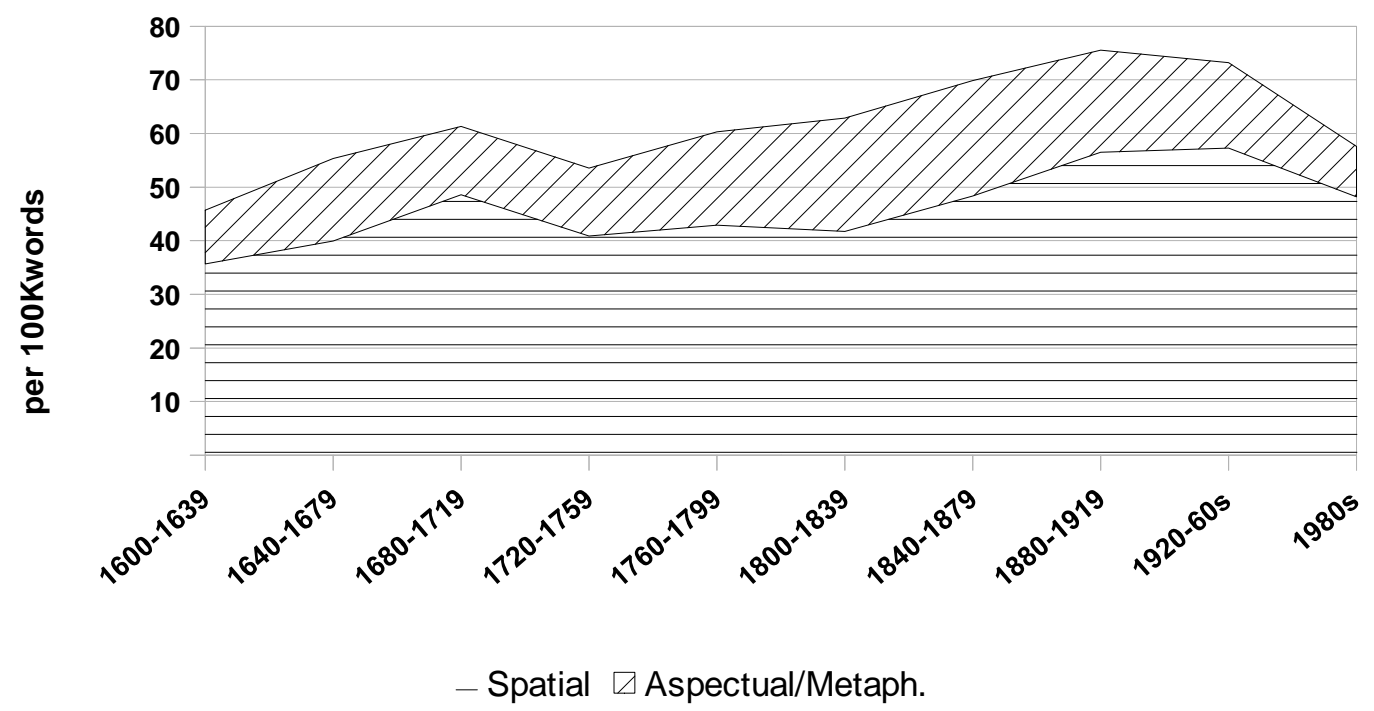

Figure 1. Evolution of token frequency of spatial and aspectual or metaphorical occurrences. 


\subsection{The development of locative 'away'}

The particles that emerge from Old English into Middle English, both from prefixes and from adverbials, rarely occur with stative and existence verbs (Hiltunen 1983:147). Hiltunen reports that activity and motion verbs together account for $95 \%$ of the particles in his data, although he notes that the basic sense of the particles is "the direction or the location of the action denoted by the verb" (1983: 146). By Early Modern English, away occurs in locative contexts, especially as away from (8).

(8) my sweethart is now away from me, but I hope his absence will not be long [1635]

Away and from will become "so closely connected as to form a kind of unit" (Poutsma 1926:718), a complex spatial preposition. But it is from the eighteenth century that away itself becomes a 'location', such as in the expressions there away and where away (now found only in non-standard varieties). And in Present-day English, the expression be away has idiomatized to mean temporary absence from the usual home or workplace (9).

$$
\text { She's been away for the last week [1980s] }
$$

From being very marginal, the locative use expands over the nineteenth century to more than a quarter of tokens (Figure 2). It thus almost entirely accounts for the rise in frequency of away over that period.

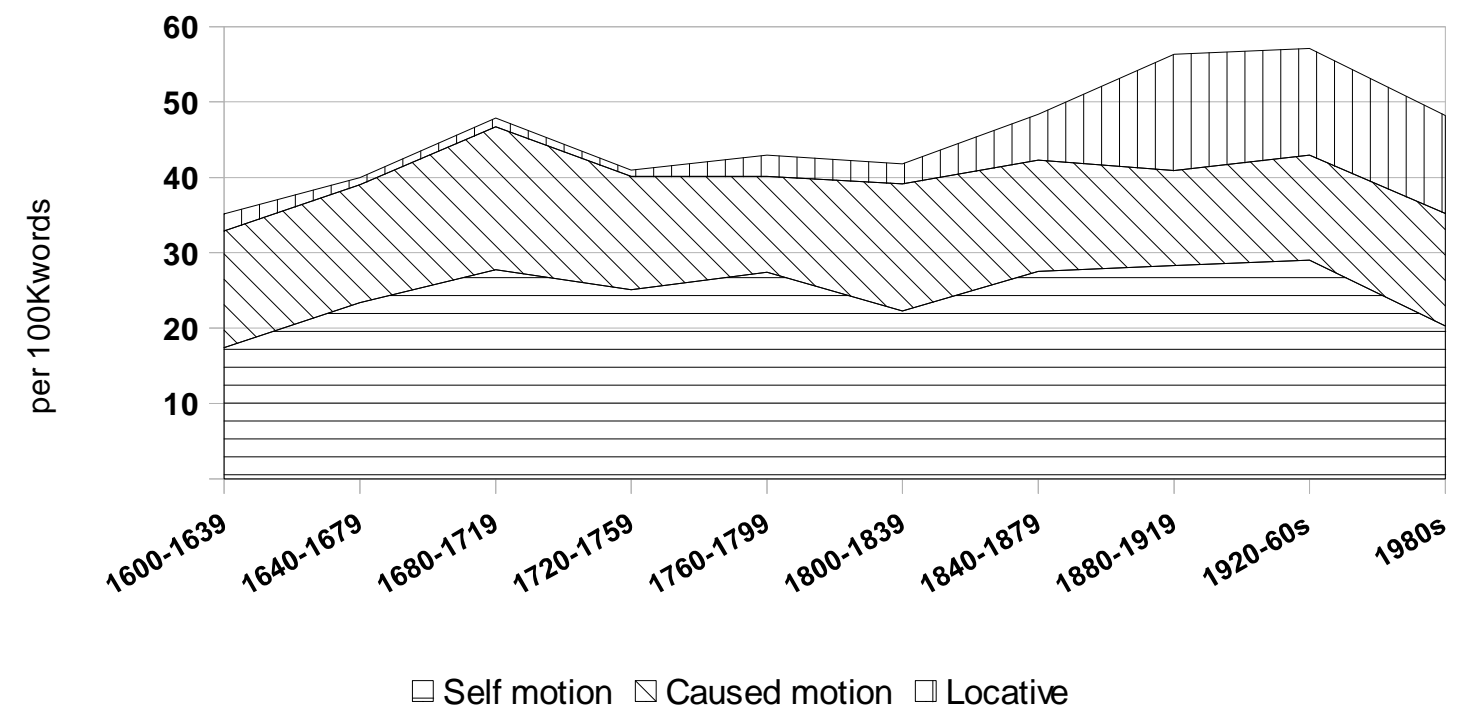

Figure 2. Spatial 'away': increase in Locative use

In Present-day Engish there can be ambiguity between the directional and the locative uses, as in (10), where two interpretations are possible: locative - V-PP [amble] [[away from] the beaches] - and directional - Vprt-PP [amble] [away] [from the beaches].

(10) for those happy to amble away from the beaches, Torbole is also surrounded by miles of peaceful lakeside trails [1980s] 
The emergence of this locative use makes sense as a resultative inference: one who has moved away is now away ( $c f$. Hovmark (2013) on Danish). The same inferencing can be seen for out, where one who has gone out is now out. It has not occurred for go off as in I'm going off; He's gone off (he's off being interpreted as 'he's leaving now'). Cross-linguistically, the reinterpretation or reanalysis of a Source expression as a Locative is well attested (Luraghi 2014), but a single marker for both Source and Location is rare. Rather, the Source sense disappears in such cases. We will return to this point in section 5 .

\section{Potential decline of directional away}

\subsection{Idiomatization / lexicalization of V-away}

The data suggest that the proportions of self and caused motion have remained rather stable (Fig. 2). This reflects the high proportions of the two categories that are accounted for by a small number of frequent combinations, in particular go, run, come and get for self-motion and take, carry, send for caused motion. Go away, run away and get away become lexicalized, gradually acquiring specialized or idiomatic meanings. Go away in the seventeenth century expresses the notion of leaving a place. It occurs repeatedly in Pepys' diaries, for example, to indicate that he or another person departed from a place where they had spent some hours, often when a visitor left his house as in (11); this use is obsolete in PDE.

\section{Mr Palmer dined with me; went away neare 5 [1685]}

Salient among the specialized present-day meanings is that exemplified in (12), where go away in the sense of going to a place other than one's habitual abode is matched by be away (see (9)). Going or being away then starts to be equated by default with the social convention of spending short periods of time elsewhere for work or leisure.

$$
\begin{aligned}
& \text { and Tara you're .. when are you going away? } \\
& \text { well we're going away erm on the Friday morning [1980s] }
\end{aligned}
$$

Likewise, run away and get away occur in particular context types where they have idiomatic meanings. Runaway and getaway have also developed uses as nouns and adjectives in the same context types. These verbs are now closely associated with scenario types. The Source Ground or the Goal Ground does not need to be mentioned. With V-away lexicalization, such as run away, usage can be said to narrow, insofar as the scenario typically associated with the combination semanticizes into it, so that it becomes difficult to use the combination in other scenarios. The sense is no longer compositional, i.e. directional motion in relation to a ground. Figure 3 shows the frequencies of the four most frequent self-motion combinations with away; between them they account for more than half of the occurrences of away in selfmotion expressions.

The overall picture, then, is one where many $V$-away combinations can not only have both an aspectual or metaphorical sense as well as a (compositional) spatial sense, but the spatial sense also splits into contextual uses. The findings seem to reflect the conserving effect of high relative frequency. (The conserving effect is described by Bybee as "the tendency of high-frequency sequences to become more entrenched ... and resist restructuring on the basis of productive patterns that might otherwise occur" (2006: 715)). The lexicalized combinations go away, run away, come away ${ }^{7}$ and get away are no longer entirely compositional, and so they become semi-detached from the paradigm. They co-exist with transparent combinations 


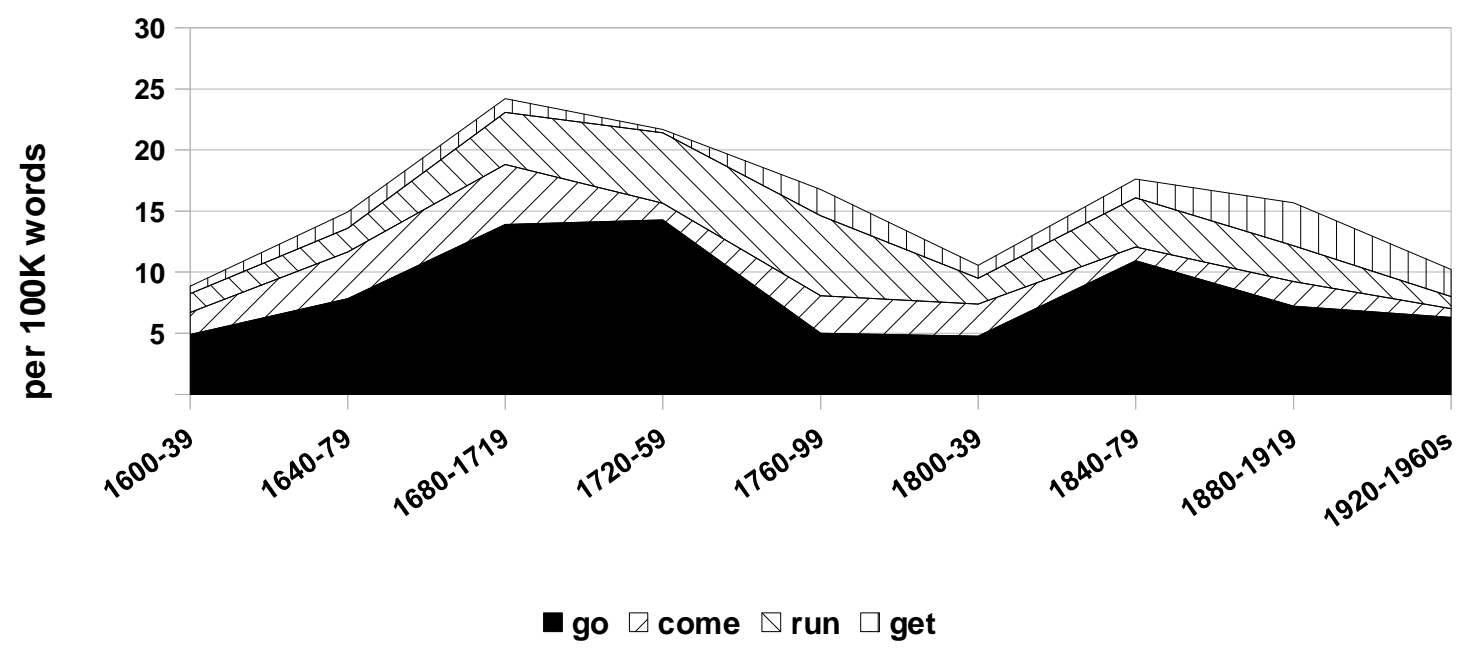

Figure 3. Frequencies of the four most frequent self-motion verbs with 'away'.

of the same forms, resulting in polysemy ([go away] and [go] [away] and so on). This can be seen in the difference between go away so far and go so far away. The default reading of the former is the lexicalized sense of (12), where the go away sequence has become inseparable and has acquired a specific meaning that must be learnt and stored in the mental lexicon. That of the latter is spatial.

\subsection{Decline of V-away and autonomous 'away'}

A number of V-away constructions have dwindled and all but dropped out of the language, though many live on in non-standard varieties. These constructions include intransitive and transitive verbs, such as flee away, escape away, vanish away, convey away, remove away, sell away, steal away (in the sense of to rob somebody of something) dispatch away, pay away which contain in themselves the notion of movement away from a location (13). For all of these, away has been dropped. It may be that away provided a default complement when no ground was mentioned, and that such verbs no longer require such a complement. Whatever the case, this change (flee away > flee; vanish away > vanish, etc.) reduces the range of verbs that combine with away.
a. we had better flee away than stay [1670s]
b. and the voice bid them begon whereupon they vanished away [1670]

The use of away as an autonomous expression of leaving (14) has been lost, except for idioms such as up and away and away with $X$.
a. Let's away [1647]
b. Whither away so speedily? [1641]

\section{3 'Away' and 'off'}

Many Present-day English manner of motion verbs combine with both away and off, such as 
wander, hurry, scamper, mosey, amble, etc. (15). V-away tends to occur in contexts of leaving some place or situation behind, while $V$-off rather connotes moving elsewhere, or at least moving purposefully, but they are nevertheless often interchangeable.

a. Catherine wandered away dejectedly. There was nothing more she could do (1980s)

b. the clerk smiled and shook his head so the fellow wandered off (1980s)

Already in Old English there is clear similarity between aweg/onweg and of ('off'); both are described by Brinton as 'directional and telic' in Old English and Middle English (1988:217228). Both are Source-oriented; off is defined as 'Expressing motion or direction from a place: to a distance, away, quite away' (OED). Originally the strong form of $o f$, meaning 'away, away from', off by Early Modern English had become a separate word. Away derives from a Path expression, which may account for its association with durativity, while off is a Source expression, associated with punctual events and detachment.

The overlap of away and off in the seventeenth century is clear; they occur with some of the same verbs in the same contexts, with small contextual or sociolinguistic variation. For example, in (16), from a murder trial, the witness Bedloe (a criminal) uses carry off when reporting what the murderers said to him, while the justices use carry away, for the same action of disposing of the body after the murder. (Both also use carry out [from] when referring to removing the body from the building.)

(16) Bedloe: if you will help to carry him off, you shall have half the Reward [...]

Bedloe: you will be at the Carrying Off of this Man at Night [...]

Lord Chief Justice: Did they discourse of carrying him away then? [...]

Justice Wild: Did not you see Hill that night when you were to have carried him away? [1679]

The uses of away and off in this discourse, by the justices and the accused respectively, reflect register differences. Many of the verbs of self-motion and caused motion that occur in the corpus are found with both away and off, in very similar contexts (17).
a. He said no more and went away (1740)
b. They soon went off together (1780)
c. Why, then, Madam, the best Way will be for you to go to him [her husband] - and let me sneak off the other Way (1757)
d. .. he tries the lady; if he finds her weak and yielding, the day's his own, and he goes off in triumph; but if she has Courage to baffle the Fool, he sneaks away with his disappointment (1725)

Lexicalized special uses of go off in the seventeenth century include the action of a gun firing and the leaving port of a ship or boat. These are dynamic and punctual events; other $V$-off occurrences tend also to refer to dynamic events; away, by contrast, connotes durative motion and gradual disappearance into the distance (consistent with the development of the aspectual uses as mentioned above), often the closing of an episode.

As has already been seen, the four most frequent self-motion verbs (go, come, run, get) account for well over half of occurrences; other verbs of self-motion are too infrequent in the corpus for conclusions to be drawn ( $v$. Fanego 2012 on the diachronic expansion of manner of motion verbs). Further clues were therefore sought in the 400-million word Corpus of Historical American English (COHA). The following verb lemmas were investigated: hurry, 
steal, fly, glide, rush, wander, sneak, march, stride, creep, dash and shuffle. All contexts and uses of the combinations were included; cases with intervening material between verb and particle were excluded. The measure is a very crude one. Moreover, American English is not directly comparable with British English, and the formal written genre bias of the COHA corpus is very different from the drama and letters corpus. But the size of COHA allows for infrequent lexemes to be found. All twelve occurred in both V-away and V-off constructions in the corpus data of the period 1820-2000. There were no cases where the away combination became more frequent than the off one, i.e. where the proportion of occurrences with away increased. Of the verbs, three, steal, glide and creep, were more frequent with away throughout the period. Seven, hurry, stride, fly, dash, sneak, wander and rush showed an increase in the proportion of combinations with off and correspondingly fewer with away, and two, shuffle and march were more frequent with off throughout the period.

A pattern of occurrences begins to emerge suggesting that a long-term trend may have begun whereby V-away cedes to V-off over time rather than remaining stable or shifting the other way round. Once such a change is set in motion, it is likely to be propagated by paradigmatic pressures, that is, by analogical reasoning. For relatively low-frequency items, speakers are likely to apply a construction from a similar context. In this way the preferred construction for a verb such as rush, for example, is likely to become aligned with that of a verb like dash, given the similar contexts of use.

A different picture emerges for the high-frequency verb walk. The frequency of walk away, consistently higher than that of walk off during the period, shoots up from the middle of the twentieth century while walk off shows little change. Such a scenario is compatible with the lexicalization process of walk away to mean to turn one's back or abandon.

\section{Possible motivations for an away $>$ off shift}

Away, then, may be increasingly replaced by off with verbs of manner of motion in what looks like a diffusional change leading to a decline in use and productivity of away. There are several plausible, mutually compatible explanations for this trend from away towards off .

First, it may be related to the 'Goal bias' that has been discussed by many researchers, whereby the greater cognitive salience of Goals over Sources leads to assymetry in the way Goals and Sources are coded in language (Bourdin 1997, Stefanowitsch and Rohlde 2004, Creissels 2006, Croft et al 2010, Papafragou 2010). Goal prominence is hypothesized to lead to more frequent expression of Goal than Source, which can result in Goals being expressed by more grammaticalized means, and in a more finely-grained manner, than Sources. The Goal preference may also be responsible for inferencing that results in semantic shifts from Source towards Goal.

If a Goal-bias were at least partly responsible for the away > off shift, we should expect to see $V$-off more associated with Goal expressions than $V$-away. The same verbs in the same selfmotion constructions were investigated for Present-day English via the British National Corpus. Table 2 shows the raw figures for the 100m-word corpus. Included are the phrasal verbs V-away and V-off with and without following expressions of Ground. There were a very few occurrences of Path PPs, such as <along NP>, and many more of Source and Goal, mainly from and to, occasional out of, $X$-wards, into. 


\begin{tabular}{|l|ccc|ccc|}
\hline Verb & $\begin{array}{l}\text { away } \\
\text { total } n\end{array}$ & $P P-S$ & $P P-G$ & $\begin{array}{l}\text { off } \\
\text { total } n\end{array}$ & $P P-S$ & $P P-G$ \\
\hline drift & 146 & 44 & 14 & 83 & 0 & 47 \\
fly & 1 & 0 & 0 & 146 & 2 & 39 \\
glide & 12 & 2 & 1 & 2 & 0 & 0 \\
hurry & 81 & 6 & 11 & 46 & 0 & 24 \\
march & 25 & 4 & 5 & 61 & 1 & 21 \\
ride & 29 & 5 & 1 & 29 & 0 & 6 \\
rush & 26 & 3 & 5 & 141 & 0 & 57 \\
sail & 36 & 4 & 2 & 20 & 0 & 9 \\
slip & 366 & 58 & 47 & 41 & 0 & 11 \\
sneak & 10 & 3 & 0 & 22 & 0 & 9 \\
steal & 21 & 5 & 3 & 0 & 0 & 0 \\
stride & 28 & 5 & 5 & 42 & 0 & 17 \\
trot & 11 & 2 & 1 & 33 & 0 & 11 \\
trudge & 5 & 1 & 2 & 16 & 0 & 8 \\
walk & 465 & 99 & 18 & 239 & 0 & 44 \\
wander & 52 & 18 & 10 & 157 & 3 & 54 \\
$\quad$ Total & $\mathbf{1 3 1 4}$ & $\mathbf{2 5 9}$ & $\mathbf{1 2 5}$ & $\mathbf{1 0 7 8}$ & $\mathbf{6}$ & $\mathbf{3 5 7}$ \\
\hline
\end{tabular}

Table 2. Occurrences in the BNC of verbs of manner (self-motion) with 'away' and 'off', with expression of Source (PP-S) and Goal $(P P-G)$

It is striking how much more frequent Goals are than Sources after the V-off constructions (less than 2\% of the Grounds mentioned are Sources). By contrast, Sources are more frequently mentioned than Goals after V-away constructions.

A second possibility is that the shift might originate as 'inflation' (Haspelmath 1999; Dahl 2001), whereby a 'stronger' expression is preferred, but in time weakens as it becomes adopted as the norm, and in time may be replaced again by a stronger item. Dahl suggests that "the initial driving force of such a process is speakers' desire to maximize the rhetorical effect of their statements" (2001:473). 'Stronger' expressions therefore tend to be the newer and less frequent ones. By contrast with away, which collocates with durative, unbounded displacements (hence its aspectual development), of/off in early phrasal verbs of Middle English denotes sudden separation or removal, as in cut off ( $v$. Brinton 1988:175f and 217f). As seen in section 5.3, off is associated with dynamic, telic events, focusing on the point of departure or separation where a sudden change occurs. If away weakens and loses combinations such as come away that express fast, dynamic events, off will appear rhetorically stronger. An illustrative example is the split between fly away, which now collocates with birds and insects that move into the distance with no obvious destination, and the newer fly off, for sudden and unexpected separations of objects as well as air travel. Expression of dynamic events anticipates some result or follow-up and is unlikely to be episode-final. V-off in self-motion contexts suggests the prelude to a future event rather than the conclusion of a past episode, which ties in with a greater focus on the Goal.

Thirdly, there may be a prosodic motivation too: off to can be considered a complex preposition analogous to into, on to, up to (cf. Where/What is he off to / up to / into / on to?). As noted above (section 4.2) away from also functions as a complex preposition, but has come to be associated with location as well as direction. It has often been noted that phrasal verbs 
prefer monosyllabic particles, so that analogy with other V-prt constructions might favour the monosyllabic off that will contribute to prosodic regularization and a 'neater' system.

The other side of the coin is an incipient decline in productivity of the motion-verb-away construction, which may not be entirely attributable to off. It may be linked to away being increasingly associated with the Locative. As mentioned in section 4.2, there seems to be cross-linguistic avoidance of Source-Location conflation in the same form, which could hamper the formation of new, transparent $\mathrm{V}$-away combinations. A further factor might be the expansion of aspectual and other non-motion combinations with away. A similar development has already affected after, which in Old English was commonly used with a range of motion verbs (Hiltunen 1983:192). V-after in the spatial sense is no longer productive at all, although frequent, entrenched, lexicalized spatial combinations are still used (such as run after, go after, hunt after). From the sixteenth century, spatial after began to be replaced by for in V-prt constructions; thus, wait after > wait for; look after > look for and so on. V-after constructions survived with non-spatial, idiomatic meanings only (as is the case for look after, restricted now to 'take care of') (v. Akimoto 2006).

Forth has also been lost to English in very similar circumstances. ${ }^{8}$ Forth was productive in the Middle English period, but has now been largely replaced by out (Akimoto 2006:25ff). It now occurs only idiomatically and in specific contexts, such as put forth, burst forth, come forth. A plausible hypothesis is that away is poised to follow suit.

\section{Conclusion}

It appears that away over the Modern English period has started to decline. Certain frequent V-away combinations have become entrenched and lexicalized. This can be seen as an example of the Conserving Effect of frequency, and is due to syntagmatic pressures (regular collocation). Away has also been seen to have lost productivity, particularly where it came into competition with off. Not only do recent verbs of directed motion combine more readily with off, but older verbs that were once more frequent with away are now in PDE more frequent with off. These observations go some way to explaining the decline in token frequency of away since the end of the nineteenth century. But the decline in directional away has been sharp, offset by the rise of the Locative use. The distribution of away over the period shows an increasing proportion of tokens corresponding to idiomatized and specialized constructions, consistent with loss of productivity and indicative of fossilization.

Much of previous diachronic research has focused on the 'set' of adverbial particles and prepositions and their role in the idiomatic phrasal verb, particularly the grammaticalization of spatial meanings into aspectual ones. The emphasis has fallen on the similarities among particles. But overall, the 'set' of English directional particles is far from neat: as Jackendoff puts it, the patterns of particle constructions "interweave in complex fashion" (2002:68). Historically, some derive from Old English prefixes, while others, including away, evolved out of adverbs to form 'new' directional particles in Middle English, a distinction which seems to have had lasting effects. There is considerable dialectal variation, especially as regards combinations of particles, and whether they occur as prepositions, adverbial particles or both. Moreover, the Source-oriented particles are particularly irregular and unstable, as attested by shifting combinations of off [of/from], out [of/from], away [from], and by much dialectal variation.

Future investigations into the changing fortunes of the directional particles, and the 
relationships among them, will be needed to see whether this decline is part of a long-term trend, and to see to what extent there is systemic change; that is, whether the particle set as a whole is undergoing some reorganization or regularization, or whether it is a local phenomenon of one particle competing with and potentially replacing another. Before further generalizations can be made, close investigation of the spatial uses of each particle will be needed.

\section{Footnotes}

1. Many verb+ particle combinations are lexicalized in the sense of having idiomatic (non-compositional) meanings that can no longer be said to evoke any type of motion or to be purely aspectual. Examples are such verbs as put up or show off. The category of 'idiomatic uses' is intended to cater for such lexemes.

2. Although little is certain about the dialectal situation of Old English, it is thought that onweg and aweg were regional variants, the latter being common in the West Saxon and Northumbrian varieties, where, it is assumed, the medial ' $n$ ' had dropped (v. Campbell 1959).

3. Present-day undated examples (1) to (7) are for background illustration; they are not part of the corpus data.

4. For further discussion of the notion 'satellite', see Grinevald 2011 and Imbert et al 2011.

5. As pointed out by Claridge (2000:46) and others, the term 'phrasal verb' is problematic and is used in different senses by different scholars. Here it is used for Verb + adverbial particle (V-prt) combinations regardless of how semantically transparent or opaque the resulting meaning is.

6. Talmy (2000:108) analyses away from in The snake is lying away from the light as a 'path preposition' that coerces the verb's semantic properties (lie $=$ motionless) into a fictive 'alignment path' interpretation where the snake is straight (not coiled) with its head farthest from the light. However, this is not the only reading of the sentence, which can equally be interpreted as the snake lying (straight or coiled) in a place where the light does not reach.

7. Come away, although well known due to the famous Come away, come away, death song in Shakespeare's Twelfth Night, is now largely obsolete in standard British English but retained in dialects, as in Northumberland howay (meaning 'come on!' from come away!).

8. In Old English away may itself have largely replaced of, the sense of which was 'away' or 'away from'.

\section{Appendix: Corpus sources}

Modern English:

A Corpus of English Dialogues 1560-1760 (Kytö and Culpeper)

A Corpus of Late Modern English Texts v.3 (H. De Smet)

The Victorian Plays Project

The Helsinki Corpus

The Archer Corpus

Additional historical texts

Present-day English:

Lancaster-Oslo-Bergen (LOB) Corpus

London-Lund Corpus

British National Corpus (BNC) world edition.

Corpus of Historical American English

\section{References}

Akimoto, Minoji. 2006. On the decline of 'after' and 'forth' in verb phrases. In Christiane Dalton-Puffer, Dieter Kastovsky and Nikolaus Ritt (eds.) Syntax, Style and Grammatical Norms: English from 1500-2000. Frankfurt-am-Main: Peter Lang, 11-31. 
Beal, Joan C. 2004. English in Modern Times: 1700-1945. London: Arnold.

Bourdin, Philippe. 1997. On goal-bias across languages: modal, configurational and orientational parameters. In B. Palek (ed.) Proceedings of $L P^{\prime} 96,185-218$.

Brinton, Laurel J. 1988. The Development of English Aspectual Systems. Cambridge: Cambridge University Press.

Bybee, Joan L. 2006. From usage to grammar: the mind's response to repetition. Language 82(4), 711-733.

Campbell, Alistair. 1959. Old English Grammar. Oxford: Clarendon Press.

Claridge, Claudia. 2000. Multi-word Verbs in Early Modern English: A Corpus-based Study. Amsterdam: Rodopi.

Creissels, Denis. 2006. Encoding the distinction between location, source and direction: a typological study. In Maya Hickmann and Stéphane Robert (eds.) Space in Languages: Linguistic Systems and Cognitive Categories. Amsterdam: John Benjamins, 19-28.

Croft, William, Johanna Barðdal, Willem B. Hollmann, Violeta Sotirova and Chiaki Taoka. 2010. Revising Talmy's typological classification of complex events. In Hans C. Boas (ed.), Contrastive Construction Grammar. Amsterdam: John Benjamins, 201-236.

Curzan, Anne. 2012. Periodization in the history of the English language. In Laurel J. Brinton and Alexander Bergs (eds.) English Historical Linguistics, vol. 2, 1233-1256.

Dahl, Östen. 2001. Inflationary effects in language and elsewhere. Joan Bybee and Paul Hopper (eds.) Frequency and the Emergece of Linguistic Structure. Amsterdam: John Benjamins, 471-480.

Fanego, Teresa. 2012. Motion events in English. The emergence and diachrony of manner salience from Old English to Late Modern English. Folia Linguistica Historica 33: 29-85.

Gries, Stefan Th. and Anatol Stefanowitsch. 2004. Extending collostructional analysis: a corpus-based perspective on 'alternations'. International Journal of Corpus Linguistics 9(1): 97-129.

Grinevald, Colette. 2011. On constructing a working typology of the expression of path. Faits de Langue. Les Cahiers 3: 43-70.

Haspelmath, Martin. 1999. Why is grammaticalization irreversible? Linguistics 37(6): 1043-68.

Hiltunen Risto. 1983. The Decline of the Prefixes and the Beginnings of the English Phrasal Verb. Turku: Turun Yliopisto.

Hiltunen, Risto. 1994. On phrasal verbs in Early Modern English. Notes on lexis and style. In Dieter Kastovsky (ed.) Studies in Early Modern English. Berlin: Mouton de Gruyter, 129-140.

Hovmark, Henrik. 2013. Danish directional adverbs: ways of profiling a motion event. In C. Paradis, J Hudson \& U. Magnusson (eds.), The Construal of Spatial Meaning: Windows into Conceptual Space. Oxford: Oxford University Press, 169-193

Imbert, Caroline, Grinevald, Colette and Söres, Anna. 2011. Pour une catégorie de "satellite" de Trajectoire dans une approche fonctionnelle-typologique. Faits de Langue. Les Cahiers no. 3: 99-116.

Jackendoff, Ray. 2002. English particle constructions, the lexicon, and the autonomy of syntax. In Nicole Dehé, Ray Jackendoff, Andrew McIntyre and Silke Urban (eds.) Verb-Particle Explorations. Berlin: Mouton de Gruyter, 67-94.

Luraghi, Silvia. 2014. Plotting diachronic semantic maps. The role of metaphor. In Silvia Luraghi and Heiko Narrog (eds.), Perspectives on Semantic Roles. Amsterdam: John Benjamins, 99-150.

OED Online. December 2016. Oxford English Dictionary, Oxford University Press. http://www.oed.com (accessed 13 February, 2017).

Papafragou, Anna. 2010. Source-goal asymmetries in motion representation: implications for language production and comprehension. Cognitive Science 34(6): 1064-1092.

Penzl, Herbert. 1994. Periodisation in language history: Early Modern English and the other periods. In Dieter Kastovsky (ed.) Studies in Early Modern English. Berlin: Mouton de Gruyter, 261-268

Poutsma, Hendrik. 1926. A Grammar of Late Modern English, Part II Section II. Groningen: Noordhoff.

Rodriguez Puente, Paula. 2013. The Development of Phrasal Verbs in British English from 1650 to 1900. A Corpus-based Study. PhD dissertation, University of Santiago de Compostela. 
Stefanowitsch Anatol and Ada Rohlde. 2004. The goal bias in the encoding of motion events. In: Radden Gunther and Klaus-Uwe Panther (eds.) Studies in Linguistic Motivation. Berlin: Mouton de Gruyter, 249-268.

Talmy, L. 1985. Lexicalization patterns: semantic structure in lexical forms. In T. Shopen (ed.) Language Typology and Syntactic Description. Cambridge: Cambridge University Press, 57-149.

Talmy, L. 2000. Toward a Cognitive Semantics. Cambridge, MA: MIT Press. 